\title{
QUALITY INSPECTION AND EVALUATION OF SATELLITE ORTHOPHOTOS IN CHINA'S THIRD NATIONAL LAND SURVEY
}

\author{
Luo Fujun $^{1}$, Li Cheng ${ }^{2, *}$, Yan Yinghua ${ }^{3}$ \\ ${ }^{1}$ National Quality Inspection and Testing Center for Surveying and Mapping Products, Beijing, China - 1254020931@qq.com \\ ${ }^{2}$ China Transport Telecommunications \&Information Center, Beijing, China - 395878359@qq.com \\ ${ }^{3}$ Zhejiang No.1 Surveying and Mapping Institute, Hangzhou, China - 413985070@qq.com
}

Commission III, WG III/IVb

KEY WORDS: China's Third National Land Survey, Satellite Orthophotos, Quality Evaluation, Fuzzy Comprehensive Evaluation, Quality Characteristics, Check Content

\begin{abstract}
:
Satellite orthophotos are important data sources and results of China's third national land survey, and their quality profoundly affects the accuracy of the survey results. This article reviews the quality requirements and quality models of satellite orthophotos for the purpose of land survey in conjunction with the quality inspection and evaluation of satellite orthophotos covering the entire land area of China, and analyzes the shortcomings of current orthophotos quality evaluation methods. On the basis of this method, a multilevel fuzzy comprehensive evaluation method was introduced to test the orthophotos quality evaluation, and the concepts of maximum membership effectiveness index and evaluation grade probability were used to constrain the evaluation results. The results prove that the method is more effective than the current method true and accurate.
\end{abstract}

\section{GENERAL INSTRUCTIONS}

\subsection{Satellite Orthophotos}

The China's third national land survey used remote sensing, surveying and mapping, geographic information, and the internet to investigate the ownership and use rights of various types of land nationwide. Satellite orthophotos are important data sources and results of China's third national land survey. They are the positioning reference and statistical basis for land survey. They determine the accuracy of the third land survey and the progress of subsequent operations. Therefore, to analyze and evaluate the quality of the orthophotos according to the content of the third land survey work, on the one hand, it can be improved and controlled in a targeted manner during the data processing to improve the orthophotos quality; on the other hand, it can be selected according to the needs of the third land survey work High-quality data sources and reducing unnecessary data processing workload are of great significance for improving the work efficiency and quality level of the results.

This paper analyzes the quality of satellite orthophotos covering the entire land area of China, and conducts corresponding research on the methods of inspection and evaluation the quality of satellite orthophotos for the application of land survey.

\subsection{Quality Requirements}

In order to meet the needs of the China's third national land survey, coordinate domestic and foreign satellite data sources, such as GF-2, BJ-2, GJ-1, JL-1A, YG series, WorldView-2 / 3/4, GeoEye-1, KOMPSAT-3 / 3A, Pleiade-1A / 1B, DEIMOS-2 etc. The resolution of satellite orthophotos must better than 1 meter. The plane position accuracy of the orthophotos should generally meet the 1: 10,000 mapping accuracy requirement, the amount of cloud (snow, fog) should not exceed $20 \%$, no large area noise and bands, no deformation of the ground caused by terrain changes, natural colors and clear textures, moderate contrast, layered, no graininess, to avoid overexposure of buildings, roads and other features, the sides of the mosaic line and adjacent images should be basically the same color, which is beneficial to cultivated land, garden land, forest land, grassland Interpretation.

\subsection{Check content}

The core inspection contents of satellite orthophotos include 14 items such as coordinate system, projection parameters, position accuracy, image edge, sharpness, etc., and a model of quality characteristics and inspection items is formed according to the hierarchical relationship, see table 1 for inspection contents.

\begin{tabular}{|c|c|l|}
\hline $\begin{array}{c}\text { Quality } \\
\text { characteristics }\end{array}$ & Check item & \multicolumn{1}{|c|}{ Inspection contents } \\
\hline $\begin{array}{c}\text { Spatial } \\
\text { reference } \\
\text { soordinate }\end{array}$ & $\begin{array}{l}\text { Accuracy of the coordinate } \\
\text { system definition } \\
\text { parameters. } \\
\text { Projection } \\
\text { parameters }\end{array}$ & $\begin{array}{l}\text { lorrectness of Gaussian } \\
\text { projection band and central } \\
\text { meridian. }\end{array}$ \\
\hline $\begin{array}{c}\text { Position } \\
\text { accuracy }\end{array}$ & $\begin{array}{c}\text { Position } \\
\text { accuracy } \\
\text { Edge }\end{array}$ & $\begin{array}{l}\text { Feature point location } \\
\text { errors and errors in } \\
\text { statistics. error between } \\
\text { Edge ers }\end{array}$ \\
\hline
\end{tabular}

\footnotetext{
* Corresponding author
} 


\begin{tabular}{|c|c|c|}
\hline & accuracy & $\begin{array}{l}\text { different images and errors } \\
\text { in statistics. }\end{array}$ \\
\hline $\begin{array}{l}\text { Logical } \\
\text { consistency }\end{array}$ & $\begin{array}{c}\text { Image } \\
\text { organizatio } \\
\mathrm{n} \\
\text { Image } \\
\text { format } \\
\end{array}$ & $\begin{array}{l}\text { Correctness of } \\
\text { organization. } \\
\text { Correctness of format and } \\
\text { version. }\end{array}$ \\
\hline Time accuracy & $\begin{array}{c}\text { Original } \\
\text { image }\end{array}$ & $\begin{array}{l}\text { Correctness of the original } \\
\text { image selection. }\end{array}$ \\
\hline Image quality & $\begin{array}{c}\text { Image } \\
\text { resolution } \\
\text { Image range } \\
\text { Color mode } \\
\text { Texture } \\
\text { feature } \\
\text { Image noise } \\
\text { Information } \\
\text { loss }\end{array}$ & $\begin{array}{l}\text { Correctness of resolution. } \\
\text { Correctness of range. } \\
\text { Accuracy of image color } \\
\text { mode and pixel bit. } \\
\text { The color is natural, the } \\
\text { color tone is uniform, the } \\
\text { details are clear, and the } \\
\text { level is clear. } \\
\text { The effect of image noise. } \\
\text { Clouds, snow, fog, and } \\
\text { shadows cover the ground, } \\
\text { and overexposure or } \\
\text { spectral overflow. }\end{array}$ \\
\hline
\end{tabular}

Table 1. Quality characteristics and inspection contents

\subsection{Inspection Method}

Coordinate system, projection parameters, image organization, image format, image range, color mode, etc. can be automatically checked by writing programs, and image resolution, texture features, image noise, and information loss seriously affect the application effect. All inspections are carried out. After all the inspections are passed, the inspection batch is composed of county-level units in the provincial administrative region, and the position accuracy and the edge of the image are sampled for sampling. See table 2 for the sample size (Luo F.J. , 2017).

\begin{tabular}{|c|c|c|c|}
\hline Lot size & Sample size & Lot size & Sample size \\
\hline 20 & 3 & $101-120$ & 11 \\
$21-40$ & 5 & $1121-140$ & 12 \\
$41-60$ & 7 & $141-160$ & 13 \\
$61-80$ & 9 & $161-180$ & 14 \\
$81-100$ & 10 & $181-200$ & 15 \\
\hline
\end{tabular}

Table 2. Lot size and sample size

\section{CURRENT QUALITY EVALUATION}

\subsection{Quality Classification}

Following the idea of the barrel theory and Chinese national standard " GB/T 18316-2008 Specifications for inspection and acceptance of quality of digital surveying and mapping achievements", the lowest score of each item is taken as the upper-level score, and the county-level unit quality score is finally obtained, and the corresponding Evaluation level, the corresponding relationship is shown in table 3 ( Deng G.Q., 2008).

\begin{tabular}{|c|c|c|c|}
\hline Score & Quality level & Score & Quality level \\
\hline$[90,100]$ & excellent & {$[60,75)$} & qualified \\
{$[75,90)$} & good & $<60$ & disqualified \\
\hline
\end{tabular}

Table 3. Quality classification

\subsection{Problem}

This method is easy to operate but rough. The processing of the lowest score is essentially a fuzzy processing of each inspection item and quality characteristic weight, and cannot fully reflect the importance of image quality.

Evaluation problems in nature are mostly ambiguous. The meaning of the evaluation level is relatively vague, and the division boundary is even more subjective. For example, a score of 75.1 is good according to this method, but it may be closer to the qualified, so it is more reasonable to describe the "intermediate state" with the degree of belonging instead of not belonging.

Introduce fuzzy comprehensive evaluation method in the evaluation instead of other evaluation methods. Using membership to describe the fuzzy quality grading boundary can overcome the shortcomings of the discontinuity of quality grading in the past (He Y.L., Dai B.L., Tao X.F., 2011). Too large will result in a lower comprehensive evaluation level, making the evaluation results more reasonable.

\section{FUZZY COMPREHENSIVE EVALUATION MODEL}

\subsection{Ideas}

There are a lot of fuzzy concepts and phenomena in the objective world. For example, what are "heavy snow", "medium snow", and "small snow", and what are "tall" and "short"?

In order to clarify the fuzzy concept mathematically, Zadeh introduced fuzzy sets. The fuzzy comprehensive evaluation method is to apply the membership theory of fuzzy mathematics to quantify some factors with unclear boundaries and difficult to quantify, and make an overall evaluation of objects subject to multiple factors.

\subsection{Principle}

First determine the factor set and evaluation level set of the evaluated object, and then determine the weight and membership vector of each factor to obtain the fuzzy evaluation matrix (Jin, J. L. , Wei, Y. M. , Ding, J., 2004). Finally, the fuzzy vector and the weight vector of the factor are fuzzycalculated and classified. Normalization, the fuzzy comprehensive evaluation results are obtained (Chen, J. , 2015).

\subsection{Factor Set, Evaluation Set, Weight Set}

The factor set of satellite orthophotos is $U=\left\{U_{1}, U_{2}, \ldots, U_{5}\right\}$, where $U_{i}$ is spatial reference, position accuracy, logical consistency, time accuracy, and image quality. $U_{i}$ can also have a subset.

The evaluation set of satellite orthophotos is $V=$ \{excellent, good, qualified, unqualified $\}$. The corresponding score interval is shown in table 3 .

The impact of each inspection item on image quality is different. Judging the image quality based on individual indicators is incomplete, and the quality requirements of images for different purposes are different ( Li Y.L ,Gao Z.G. , Han Y.L., 2006). In order to reflect the importance of each factor, the weight of each factor is determined. The weight vector $W=\left\{W_{1}, W_{2}, \ldots\right.$, $W_{5}$ \} corresponding to factor $U$ and the m check items of factor 
$U_{i}$ can form a sub weight vector $W_{i}=\left\{w_{i 1}, w_{i 2}, \ldots, w_{i m}\right\}$, as shown in table 4.

\subsection{Membership Calculation}

In order to facilitate the calculation, the linear membership function is used to calculate the membership, as shown in figure 1.

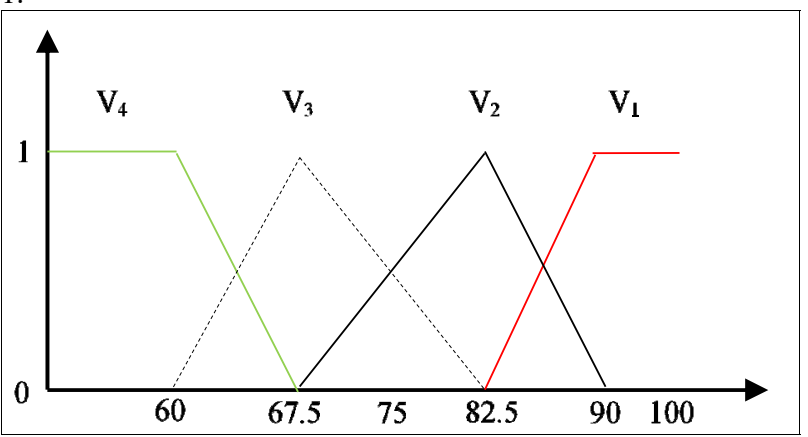

Figure 1. Linear membership function

\begin{tabular}{|c|c|c|c|c|c|}
\hline No. & $\begin{array}{c}\text { Quality } \\
\text { characteristic }\end{array}$ & Weight & $\begin{array}{c}\text { Check } \\
\text { content }\end{array}$ & Weight & Score \\
\hline \multirow{2}{*}{1} & \multirow{2}{*}{$\begin{array}{c}\text { Spatial } \\
\text { reference }\end{array}$} & \multirow{2}{*}{0.2} & $\begin{array}{l}\text { coordinate } \\
\text { system }\end{array}$ & 0.5 & 100 \\
\hline & & & $\begin{array}{l}\text { Projection } \\
\text { parameters }\end{array}$ & 0.5 & 100 \\
\hline \multirow{2}{*}{2} & \multirow{2}{*}{$\begin{array}{l}\text { Position } \\
\text { accuracy }\end{array}$} & \multirow{2}{*}{0.2} & $\begin{array}{l}\text { Position } \\
\text { accuracy }\end{array}$ & 0.5 & 74 \\
\hline & & & $\begin{array}{c}\text { Edge } \\
\text { accuracy }\end{array}$ & 0.5 & 90 \\
\hline \multirow[t]{2}{*}{3} & \multirow{2}{*}{$\begin{array}{l}\text { Logical } \\
\text { consistency }\end{array}$} & \multirow[t]{2}{*}{0.1} & $\begin{array}{c}\text { Image } \\
\text { organizatio } \\
\mathrm{n}\end{array}$ & 0.5 & 100 \\
\hline & & & $\begin{array}{l}\text { Image } \\
\text { format }\end{array}$ & 0.5 & 100 \\
\hline 4 & $\begin{array}{c}\text { Time } \\
\text { accuracy }\end{array}$ & 0.1 & $\begin{array}{c}\text { Original } \\
\text { image }\end{array}$ & 1.0 & 100 \\
\hline \multirow{6}{*}{5} & \multirow{6}{*}{$\begin{array}{l}\text { Image } \\
\text { quality }\end{array}$} & \multirow{6}{*}{0.4} & $\begin{array}{c}\text { Image } \\
\text { resolution }\end{array}$ & 0.1 & 100 \\
\hline & & & $\begin{array}{l}\text { Image } \\
\text { range }\end{array}$ & 0.1 & 100 \\
\hline & & & Color mode & 0.1 & 100 \\
\hline & & & $\begin{array}{l}\text { Texture } \\
\text { feature }\end{array}$ & 0.4 & 80 \\
\hline & & & Image noise & 0.1 & 88 \\
\hline & & & $\begin{array}{c}\text { Information } \\
\text { loss }\end{array}$ & 0.2 & 95 \\
\hline
\end{tabular}

Table 4. Weight and quality score

According to the inspection results, calculate and calculate the quality score of each inspection item of the sample $X=\left\{X_{l}\right.$, $\left.X_{2}, \ldots, X_{5}\right\}$, see Table 4, determine the evaluation level of each inspection item from this value, and finally according to the fuzzy from $U$ to $V$ Map the relationship, get the evaluation matrix of each factor, and get the evaluation level of the sample, and the evaluation level of the sample, the weight of the sample can be determined by the area and length (Ying, L.U. , 2007). The mapping relationship is given by equations (1) to (4).

$$
V_{1}= \begin{cases}0 & X \leq 82.5 \\ (X-82.5) / 7.5 & 82.5<X<90 \\ 1 & 90 \leq X \leq 100\end{cases}
$$

$$
\begin{gathered}
V_{2}= \begin{cases}(X-67.5) / 15 & 67.5<X \leq 82.5 \\
(90-X) / 7.5 & 82.5<X<90 \\
0 & \text { others }\end{cases} \\
V_{3}= \begin{cases}(X-60) / 7.5 & 60<X \leq 67.5 \\
(82.5-X) / 15 & 67.5<X<82.5 \\
0 & \text { others }\end{cases} \\
V_{4}= \begin{cases}1 & X \leq 60 \\
(67.5-X) / 7.5 & 60<X<67.5 \\
0 & \text { others }\end{cases}
\end{gathered}
$$

A fuzzy operator $M(\circ, \oplus)$ with a large clear domain is used.

$$
R_{1}=\left[\begin{array}{ll}
0.5 & 0.5
\end{array}\right]\left[\begin{array}{llll}
1 & 0 & 0 & 0 \\
1 & 0 & 0 & 0
\end{array}\right]=\left[\begin{array}{llll}
1 & 0 & 0 & 0
\end{array}\right]
$$

$$
\begin{aligned}
& R_{2}=\left[\begin{array}{ll}
0.5 & 0.5
\end{array}\right]\left[\begin{array}{cccc}
0 & 0.43 & 0.57 & 0 \\
1 & 0 & 0 & 0
\end{array}\right]=\left[\begin{array}{llll}
0.5 & 0.215 & 0.285 & 0
\end{array}\right](6) \\
& R_{3}=\left[\begin{array}{ll}
0.5 & 0.5
\end{array}\right]\left[\begin{array}{llll}
1 & 0 & 0 & 0 \\
1 & 0 & 0 & 0
\end{array}\right]=\left[\begin{array}{llll}
1 & 0 & 0 & 0
\end{array}\right] \\
& R_{4}=\left[\begin{array}{llll}
1 & 0 & 0 & 0
\end{array}\right]
\end{aligned}
$$

$$
R_{5}=\left[\begin{array}{llllll}
0.1 & 0.1 & 0.1 & 0.4 & 0.1 & 0.2
\end{array}\right]\left[\begin{array}{lccc}
1 & 0 & 0 & 0 \\
1 & 0 & 0 & 0 \\
1 & 0 & 0 & 0 \\
0 & 0.83 & 0.17 & 0 \\
0.73 & 0.27 & 0 & 0 \\
1 & 0 & 0 & 0
\end{array}\right]
$$$$
=\left[\begin{array}{llll}
0.57 & 0.36 & 0.07 & 0
\end{array}\right]
$$

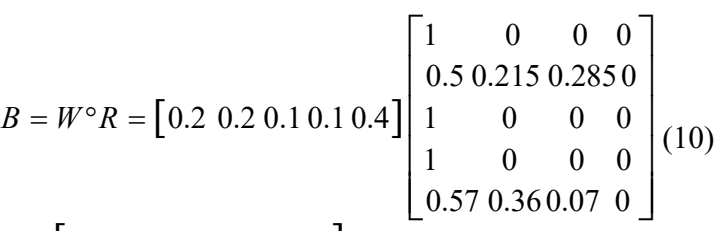

$$
\begin{aligned}
& =\left[\begin{array}{llll}
0.728 & 0.187 & 0.085 & 0
\end{array}\right]
\end{aligned}
$$

\subsection{Effectiveness index}

The relative index of validity of the principle of maximum membership is defined as (Qiu D., 1991):

$$
\alpha=\frac{n \beta-1}{2 \gamma(n-1)}
$$

where

$$
\begin{aligned}
& \beta=\max _{1 \leq i \leq n} V_{i} \\
& \gamma=\sec _{1 \leq i \leq n} V_{i}
\end{aligned}
$$

$\mathrm{n}$ is the number of factors 
When $\alpha \geq 1$, the principle of maximum membership was very effective. When $0.5 \leq \alpha<1$, the principle of maximum membership was more effective. When $0<\alpha<0.5$, the principle of maximum membership was inefficient. When $\alpha=0$, the principle of maximum membership was completely invalid.

Calculate the highest and lowest scores corresponding to the evaluation set, and calculate the probability of the evaluation results at each quality level according to the distribution ratio of the highest and lowest score intervals in each quality level interval ( Bresenham JE., 1965), See Figure 2.

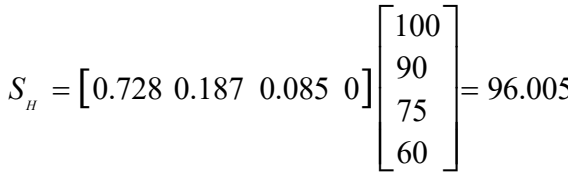

$$
\begin{aligned}
& S_{L}=\left[\begin{array}{llll}
0.728 & 0.187 & 0.085 & 0
\end{array}\right]\left[\begin{array}{l}
90 \\
75 \\
60 \\
0
\end{array}\right]=84.645
\end{aligned}
$$

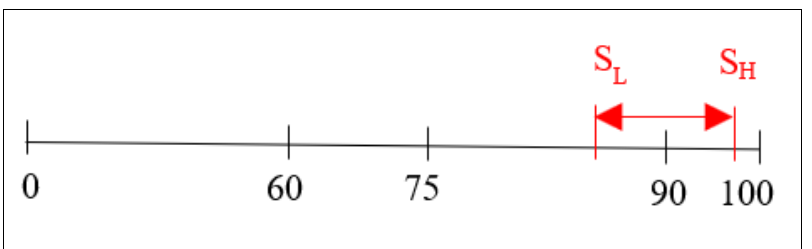

Figure 2. Quality level distribution probability
The component deviation between $(\beta-\gamma)$ and the ratio of $\sum_{i=1}^{n}\left|b_{i}-\bar{b}\right|$ can reflect the effectiveness of the principle of maximum membership. $\quad C v=(\beta-\gamma) / \sum_{i=1}^{n}\left|b_{i}-\bar{b}\right| \quad$, $C v \in\left(0, \frac{n}{2(n-1)}\right)$, the larger the $C v$, the more effective the principle of maximum membership. Taking the evaluation vector is $B=(0.728,0.187,0.085,0)$ as an example, $C v=0.566$. At this time, the principle of maximum membership is valid, and the object $\mathrm{C}$ can be evaluated as a superior product with a high probability.

\section{EXPERIMENT}

Taking the China's third national land survey satellite orthophotos quality evaluation as an example (table 5 is Anhui province inspection results), a fuzzy comprehensive evaluation was carried out and compared with the evaluation results using the GB/T18316 method, see table 6 . The results show that the weight setting not only fully reflects the special requirements for the image quality of the project application, but also takes into account the need for location accuracy; the fuzzy comprehensive evaluation method is generally upgraded by a level compared with the evaluation results of the GB/T 18316 method. The minimum score system will be subject to evaluation bias due to the abnormal influence of indicators of general factors; the deviation ratio, single-valued distribution probability method, and relative validity index can effectively evaluate the principle of maximum membership; the overall quality of the orthographic image of the third national land survey satellite is Excellent to meet the quality requirements of project design.

\begin{tabular}{|c|c|c|c|c|c|c|c|c|c|c|c|c|c|}
\hline \multirow{2}{*}{$\begin{array}{c}\mathrm{Sa} \\
\mathrm{mpl} \\
\mathrm{e}\end{array}$} & \multicolumn{2}{|c|}{ Spatial reference } & \multicolumn{2}{|c|}{$\begin{array}{l}\text { Position } \\
\text { accuracy }\end{array}$} & \multicolumn{2}{|c|}{$\begin{array}{c}\text { Logical } \\
\text { consistency }\end{array}$} & \multirow{2}{*}{$\begin{array}{c}\text { Time } \\
\text { accuracy } \\
\text { Original } \\
\text { image }\end{array}$} & \multicolumn{6}{|c|}{ Image quality } \\
\hline & $\begin{array}{l}\text { Coordinate } \\
\text { system }\end{array}$ & $\begin{array}{l}\text { Projection } \\
\text { parameters }\end{array}$ & $\begin{array}{l}\text { Position } \\
\text { accuracy }\end{array}$ & $\begin{array}{c}\text { Edge } \\
\text { accuracy }\end{array}$ & $\begin{array}{c}\text { Image } \\
\text { organization }\end{array}$ & $\begin{array}{l}\text { Image } \\
\text { format }\end{array}$ & & $\begin{array}{l}\text { Image } \\
\text { resolution }\end{array}$ & $\begin{array}{l}\text { Image } \\
\text { range }\end{array}$ & $\begin{array}{l}\text { Color } \\
\text { mode }\end{array}$ & $\begin{array}{l}\text { Color } \\
\text { mode }\end{array}$ & $\begin{array}{l}\text { Image } \\
\text { noise }\end{array}$ & $\begin{array}{c}\text { Informatio } \\
\text { n loss }\end{array}$ \\
\hline A & 100 & 100 & 79 & 85 & 100 & 100 & 100 & 100 & 100 & 100 & 92 & 96 & 97 \\
\hline B & 100 & 100 & 81 & 90 & 100 & 100 & 100 & 100 & 100 & 100 & 90 & 95 & 91 \\
\hline $\mathrm{C}$ & 100 & 100 & 79 & 83 & 100 & 100 & 100 & 100 & 100 & 100 & 87 & 95 & 94 \\
\hline $\mathrm{D}$ & 100 & 100 & 85 & 96 & 100 & 100 & 100 & 100 & 100 & 100 & 94 & 98 & 99 \\
\hline E & 100 & 100 & 86 & 96 & 100 & 100 & 100 & 100 & 100 & 100 & 83 & 89 & 90 \\
\hline $\mathrm{F}$ & 100 & 100 & 86 & 98 & 100 & 100 & 100 & 100 & 100 & 100 & 90 & 97 & 96 \\
\hline G & 100 & 100 & 77 & 85 & 100 & 100 & 100 & 100 & 100 & 100 & 90 & 92 & 92 \\
\hline $\mathrm{H}$ & 100 & 100 & 69 & 78 & 100 & 100 & 100 & 100 & 100 & 100 & 92 & 94 & 97 \\
\hline I & 100 & 100 & 85 & 94 & 100 & 100 & 100 & 100 & 100 & 100 & 89 & 93 & 91 \\
\hline $\mathrm{J}$ & 100 & 100 & 79 & 89 & 100 & 100 & 100 & 100 & 100 & 100 & 84 & 86 & 93 \\
\hline $\mathrm{K}$ & 100 & 100 & 74 & 88 & 100 & 100 & 100 & 100 & 100 & 100 & 92 & 95 & 91 \\
\hline
\end{tabular}

Table 5. Partial inspection results of the third national land survey satellite orthophotos quality (Anhui Province)

\begin{tabular}{|c|c|c|c|c|c|c|c|c|c|}
\hline \multirow{3}{*}{ Sample } & \multicolumn{8}{|c|}{ Fuzzy comprehensive } & \multirow{3}{*}{$\begin{array}{c}\text { GB/T } \\
18316\end{array}$} \\
\hline & \multirow{2}{*}{$B$} & \multirow{2}{*}{$\alpha$} & \multirow{2}{*}{$S_{H}$} & \multirow{2}{*}{$S_{L}$} & \multicolumn{2}{|c|}{$P$} & \multirow{2}{*}{$C v$} & \multirow{2}{*}{ Quality level } & \\
\hline & & & & & Excellent & Good & & & \\
\hline A & $(0.83,0.14,0.02,0)$ & 2.76 & 97.98 & 87.15 & 0.74 & 0.26 & 0.59 & excellent & good \\
\hline B & $(0.90,0.09,0.01,0)$ & 4.81 & 98.85 & 88.35 & 0.84 & 0.16 & 0.62 & excellent & good \\
\hline $\mathrm{C}$ & $(0.74,0.23,0.02,0)$ & 1.42 & 97.08 & 85.79 & 0.63 & 0.37 & 0.52 & excellent & good \\
\hline
\end{tabular}




\begin{tabular}{|c|c|c|c|c|c|c|c|c|c|}
\hline \multirow{3}{*}{ Sample } & \multicolumn{8}{|c|}{ Fuzzy comprehensive } & \multirow{3}{*}{$\begin{array}{c}\mathrm{GB} / \mathrm{T} \\
18316\end{array}$} \\
\hline & \multirow{2}{*}{$B$} & \multirow{2}{*}{$\alpha$} & \multirow{2}{*}{$S_{H}$} & \multirow{2}{*}{$S_{L}$} & \multicolumn{2}{|c|}{$P$} & \multirow{2}{*}{$C v$} & \multirow{2}{*}{ Quality level } & \\
\hline & & & & & Excellent & Good & & & \\
\hline $\mathrm{D}$ & $(0.93,0.07,0,0)$ & 6.48 & 99.33 & 89.00 & 0.90 & 0.10 & 0.63 & excellent & good \\
\hline $\mathrm{E}$ & $(0.79,0.21,0,0)$ & 1.71 & 97.92 & 86.88 & 0.72 & 0.28 & 0.54 & excellent & good \\
\hline $\mathrm{F}$ & $(0.95,0.05,0,0)$ & 9.33 & 99.47 & 89.20 & 0.92 & 0.08 & 0.64 & excellent & good \\
\hline G & $(0.83,0.13 .0 .04,0)$ & 2.97 & 97.78 & 86.95 & 0.72 & 0.28 & 0.63 & excellent & good \\
\hline $\mathrm{H}$ & $(0.80,0.08,0.12,0)$ & 3.06 & 96.20 & 85.20 & 0.56 & 0.44 & 0.62 & excellent & qualified \\
\hline I & $(0.91,0.09,0,0)$ & 4.89 & 99.12 & 88.68 & 0.87 & 0.13 & 0.62 & excellent & good \\
\hline $\mathrm{J}$ & $(0.74,0.24,0.02,0)$ & 1.36 & 97.02 & 85.71 & 0.62 & 0.38 & 0.51 & excellent & good \\
\hline $\mathrm{K}$ & $(0.80,0.12,0.08,0)$ & 3.06 & 96.80 & 85.80 & 0.62 & 0.38 & 0.62 & excellent & qualified \\
\hline
\end{tabular}

\section{CONCLUSION}

The result of fuzzy comprehensive evaluation is a vector, which reflects the fuzzy attributes of quality itself, and avoids the errors caused by rigid quality evaluation. Fuzzy comprehensive evaluation is generally performed on an object-by-object basis. As long as the evaluation index weights and composition operators are the same for the same object, the evaluation results are unique and have nothing to do with the set of objects This method can be applied to the quality evaluation of DLG, DEM and other products after reforming the quality factors and weights.

The fuzzy comprehensive evaluation process itself cannot solve the problem of duplication of evaluation information caused by correlation between evaluation factors. Each component of the evaluation vector is weighted by various factors, which reflects how much factors belong to a certain level. If no factor has a membership relationship to a certain evaluation level, the degree of membership of the level must be zero after synthesis. Therefore, the information of the evaluation vector is divergent rather than comprehensive. At the same time, the extraction of quality factors, the determination of weights, the division of evaluation levels, the design of membership functions, and the selection of synthetic operators all need to be verified to ensure the reliability and rationality of the evaluation results.

\section{ACKNOWLEDGEMENTS}

Founded by National Natural Science Foundation of China ( 41671440 ) and Wings of Quality QICS ( 2019-zlzy-011 ).

\section{REFERENCES}

Bresenham JE., 1965: Algorithm for computer control of a digital plotter. IBM System Journal, 1965, 4 (1): 25-30.

He Y.L., Dai B.L., Tao X.F., 2011: Fuzzy Comprehensive Evaluation of Surface Water Quality Based on Confidence Criteria. China Water \& Wastewater: 52-55.

Qiu D., 1991: Systematic Analysis of Multi-index Comprehensive Evaluation Method. China Statistics Press: 103-107.

Deng G.Q., 2008: Specifications for inspection and acceptance of quality of digital surveying and mapping achievements. China Standard Press: 15.
Jin, J. L., Wei, Y. M., Ding, J., 2004: Fuzzy comprehensive evaluation model based on improved analytic hierarchy process. Journal of Hydraulic Engineering(2): 144-147.

Ying, L.U., 2007. Fuzzy comprehensive evaluation for comprehensive competitiveness of enterprises. Journal of liaoning technical university.

Luo F.J., 2017. Discussion on the Use of GB/T 18316 - 2008. Ggeomatics \& Spatial Information Technology, 2017, 40 (3): 54-56.

Chen J., 2015). Evaluating teaching performance based on fuzzy AHP and comprehensive evaluation approach. Applied Soft Computing: 100-108.

Li Y.L., Gao Z.G., Han Y.L., 2006. The Determination of Weight Value and the Choice of Composite Operator s in Fuzzy Comprehensive Evaluation. Computer Engineering and Applications, 2006, 23: 38-43. 